\title{
Incidence, Risk Factors and Immediate Outcome of Preterm Neonates: A Hospital Based Study
}

\author{
Acharya $\mathrm{N}^{1}$, Poudel $\mathrm{S}^{2}$
}

\section{ABSTRACT}

Introduction: Preterm birth is defined as birth before 37 completed weeks of gestation. It is one of the leading cause of infant morbidity and mortality in the world. Aim: The study was aimed to find out the incidence, possible risk factors and outcome of inborn preterm babies till they were discharged from the hospital. Methods: This is a prospective hospital based study. A total of 100 preterm babies delivered in Nepalgunj Medical College Teaching Hospital, Kohalpur and admitted in Neonatal Intensive Care Unit (NICU) were studied. Preterms were divided into 2 groups extremely to very preterm ( $<32$ weeks) and moderate to late preterm ( $\geq 32$ weeks). The preterm babies were evaluated for various morbidities sand mortality till they were discharged from the hospital. Results: Data of 100 babies was analyzed. Out of 100 preterm babies 40 were extremely to very preterm babies $(<32$ weeks) and 60 were moderate to late preterm babies ( $\geq 32$ weeks). Significant risk factors associated with preterm deliveries were inadequate antenatal visits $(73 \%)$, primi gravidity $(58 \%)$, preterm premature rupture of membrane $(55 \%)$, urinary tract infection $(54 \%)$, anemia $(53 \%)$, teenage pregnancy $(43 \%)$, antepartum hemorrhage $(41 \%)$ and pregnancy induced hypertension (33\%). The total mortality was higher in extremely to late preterm than in moderate to late preterm. The most common causes of mortality were Neonatal sepsis (NNS), Hyaline Membrane Disease (HMD) and Birth Asphyxia. Conclusion: The hospital incidence of preterm neonates is still very high. The major risk factor seen in the study was inadequate antenatal visit. Preventive measures, early identification of risk factors will improve the outcome.

\section{Keywords: Morbidity, Mortality, Preterm, Risk factor}

Author:

1. Dr. Niraj Acharya

2. Dr. Sumita Poudel

${ }^{1}$ Department of Pediatrics, Nepalgunj Medical College and Teaching Hospital, Kohalpur, Banke

${ }^{2}$ Department of Pediatrics, Chitwan Medical College, Bharatpur, Chitwan

\section{Address for Correspondence:}

\author{
Dr. Niraj Acharya \\ Assistant Professor \\ Department of Pediatrics \\ Nepalgunj Medical College and Teaching Hospital \\ Kohalpur, Banke, Nepal \\ Email:drnirajacharya@gmail.com
}

\section{INTRODUCTION}

Preterm birth is the leading cause of infant morbidity and mortality in the world. World Health Organization (WHO) defines preterm birth as any birth before 37 completed weeks of gestation or fewer than 259 days since the first day of woman's last menstrual period (LMP). ${ }^{1}$ It is subcategorized on the basis of gestational age: extremely preterm ( $<28$ weeks), very preterm ( 28 to $<32$ weeks), moderate to late preterm ( 32 to $<37$ weeks). It has been reported that over $60-80 \%$ of all neonatal mortality and morbidity is due to preterm birth. ${ }^{2}$ Preterm birth complications account for $35 \%$ of the estimated 3.1 million global neonatal deaths and are the second leading cause of death in children under 5 years of age. ${ }^{3}$ The etiology of preterm birth is multi-factorial and categorized as either spontaneous or indicated. Spontaneous preterm birth occurs secondary to either preterm labor or preterm premature rupture of membranes (PPROM). Indicated preterm births are those that occur because of medical or obstetric problem that places either the mother or the fetus at risk; delivery is undertaken to preserve or improve the maternal or fetalstatus. ${ }^{4}$ In developing countries, the main causes of preterm births include infectious diseases and poor availability and accessibility of health care resources. Families of low socioeconomic status have higher rates of maternal undernutrition, anemia and illness, inadequate prenatal care, drug misuse, obstetric complications and maternal history of reproductive inefficiency (abortions, still-births, premature or low birth weight infants). ${ }^{5}$ Preterm babies are at increased risk of mortality and morbidity, mainly due to infections and complications of prematurity. A better understanding of antenatal factors contributing to 
preterm birth and need for improvement of perinatal care are necessary to prevent preterm births and to increase neonatal survival. Hence this study was conducted.

\section{METHODS}

A hospital based prospective study was carried out to estimate the incidence, risk factors and outcome of preterm neonates from May 2017 to April 2018., admitted in NICU department of Pediatrics, Nepalgunj Medcial College and Teaching Hospital Kohalpur.

They were divided in two groups extremely preterm $(<32$ weeks) and moderate to late preterm ( $>32$ weeks). The consent was obtained from the Parents. Those not willing to take part in the study were excluded. Ethical clearance from Institutional Review Committee, NGMC, Kohalpur was obtained. Data regarding the demographic parameters like maternal age, parity, literacy status, socioeconomic status, antenatal checkup, gestational age, mode of delivery were recorded in structural questionnaire.

Neonatal parameters like perinatal asphyxia, Apgar score, sex, gestational age, birth weight were recorded for maximum one week. All the data were analyzed by using SPSS version 20 .

\section{RESULTS}

There were 3978 birth during the study period. Total alive preterm babies were 367 (9.22\%). Among them 71 (19.34\%) were extremely to very preterm and 296 (80.65\%) were moderate to late preterm. (Figure 1)

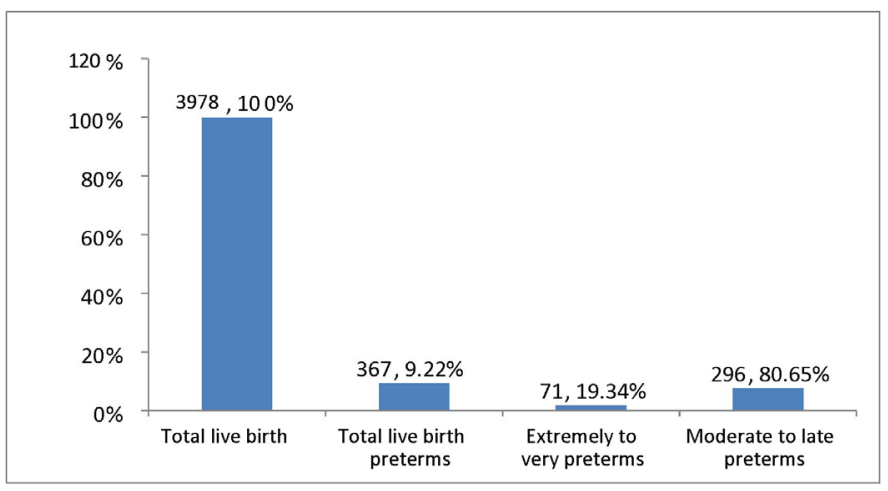

Figure 1 : Incidence of preterm birth at hospital

Out of 1410 NICU admission, 192(13.61\%) preterm were admitted in NICU and 57 (29.68\%) were extremely to very preterm and $135(70.31 \%)$ were moderate to late preterm. The Parents of 92 preterm babies in NICU did not consent to take part in the study. Hence 100 preterm were taken out of which 40 were extremely to very preterm ( $<32$ weeks) and60 were moderate to late preterm ( $>32$ weeks).

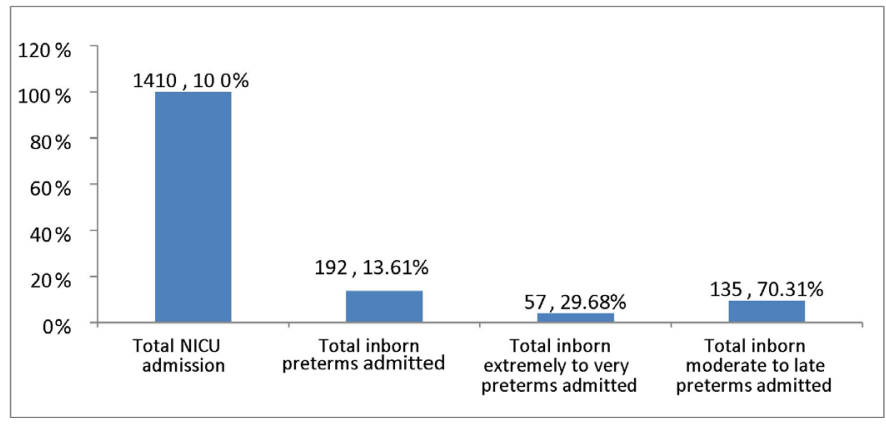

Figure 2: Preterm babies admitted in NICU

When the risk factors were analyzed it was found that the inadequate antenatal visits (73\%) was the commonest cause of preterm births followed by prim gravidity (58\%), PROM (55\%). (Table I)

\begin{tabular}{|lcc|}
\hline \multicolumn{1}{|c}{ Risk factors } & $\begin{array}{c}\text { Number of } \\
\text { patients }\end{array}$ & Percentage \\
\hline Inadequate antenatal visits & 73 & 73 \\
\hline Primigravidity & 58 & 58 \\
\hline $\begin{array}{l}\text { Preterm Premature Rupture of } \\
\text { membrane (PPROM) }\end{array}$ & 55 & 55 \\
\hline Urinary Tract Infection (UTI) & 54 & 54 \\
\hline Anemia & 53 & 53 \\
\hline Teenage pregnancy & 43 & 43 \\
\hline Antepartum hemorrhage (APH) & 41 & 41 \\
\hline Pregnancy Induced Hypertension (PIH) & 33 & 33 \\
\hline
\end{tabular}

Table I : Risk factors for preterm births in relation with maternal illnesses

In our study, maximum number of extremely to very preterm group ( $<32$ weeks) belonged to very low birth weight ( $\geq 1000$ $1500 \mathrm{gm}$ ) comprising of $85 \%$ while maximum number of moderate to late preterm babies ( $\geq 32$ weeks) belonged to low birth weight ( $>1500-2500 \mathrm{gm}$ ) comprising of $50 \%$. These values also showed a statistically significant association between gestational age and birth weight $(p<0.05)$. (Table II)

\begin{tabular}{cccccccc} 
Birth weight & \multicolumn{9}{c}{ Gestational age } & & \\
(gms) & $<32$ weeks & \multicolumn{2}{c}{$\geq \mathbf{3 2}$ weeks } & Total & $\begin{array}{c}\text { p- } \\
\text { value }\end{array}$ \\
& Number & $\%$ & Number & $\%$ & & \\
$<1000$ & 3 & 7.5 & 1 & 1.6 & 4 & \\
$\geq 1000-1500$ & 34 & 85 & 29 & 48.4 & 63 & $<0.01$ \\
\hline$>1500-2500$ & 3 & 7.5 & 30 & 50 & 33 & \\
\hline
\end{tabular}

Table II : Relation between gestational age and birth weight

Among extremely to very preterm babies, 31 (77.5\%) out of 40 survived whereas 57 (95\%) out of 60 of moderate to late preterm survived. The main causes of mortality were Neonatal Sepsis (NNS), Hyaline Membrane Disease (HMD) and Birth Asphyxia. (Table III) 


\begin{tabular}{|c|c|c|c|c|c|c|}
\hline \multirow{3}{*}{ Survival } & \multicolumn{4}{|c|}{ Gestational age } & \multirow{3}{*}{ Total } & \multirow{3}{*}{$\begin{array}{c}\mathbf{p}- \\
\text { value }\end{array}$} \\
\hline & \multicolumn{2}{|c|}{$<32$ weeks } & \multicolumn{2}{|c|}{$\geq 32$ weeks } & & \\
\hline & Number & $\%$ & Number & $\%$ & & \\
\hline Alive & 31 & 77.5 & 57 & 95 & 88 & \\
\hline Deaths & 9 & 22.5 & 3 & 5 & 12 & $<0.01$ \\
\hline Total & 40 & 100 & 60 & 100 & 100 & \\
\hline
\end{tabular}

Table III : Survival of preterm babies

Various immediate outcomes of preterm in extremely to very preterm ( $<32$ weeks) and moderate to late preterm group ( $\geq 32$ weeks) are shown in Table IV. Majority morbidities and majority of morbidities were observed in extremely to very preterm group (<32 weeks).

\begin{tabular}{|c|c|c|c|}
\hline \multirow[b]{2}{*}{ Outcomes } & \multicolumn{2}{|c|}{ Gestational Age } & \multirow{2}{*}{$\begin{array}{l}\text { Total } \\
\text { (\%) }\end{array}$} \\
\hline & $\begin{array}{c}<32 \text { weeks } \\
(n=40)\end{array}$ & $\begin{array}{c}\geq 32 \text { weeks } \\
(n=60)\end{array}$ & \\
\hline Neonatal Sepsis (NNS) & $\begin{array}{c}36 \\
(90 \%)\end{array}$ & $\begin{array}{c}32 \\
(53.3 \%)\end{array}$ & 68 \\
\hline Neonatal Jaundice (NNJ) & $\begin{array}{c}30 \\
(75 \%)\end{array}$ & $\begin{array}{c}29 \\
(48.4 \%)\end{array}$ & 59 \\
\hline Hyaline Membrane Disease ( HMD ) & $\begin{array}{c}20 \\
(50 \%)\end{array}$ & $\begin{array}{c}9 \\
(15 \%)\end{array}$ & 29 \\
\hline Birth Asphyxia & $\begin{array}{c}16 \\
(40 \%)\end{array}$ & $\begin{array}{c}15 \\
(25 \%)\end{array}$ & 31 \\
\hline Apnea of Prematurity & $\begin{array}{c}6 \\
(15 \%)\end{array}$ & $\begin{array}{c}4 \\
(6.6 \%)\end{array}$ & 10 \\
\hline Hypoglycemia & $\begin{array}{c}6 \\
(15 \%)\end{array}$ & $\begin{array}{c}5 \\
(8.33 \%)\end{array}$ & 11 \\
\hline Anemia & $\begin{array}{c}6 \\
(15 \%)\end{array}$ & $\begin{array}{c}2 \\
(3.33 \%)\end{array}$ & 8 \\
\hline Hypothermia & $\begin{array}{c}3 \\
(7.5 \%)\end{array}$ & $\begin{array}{c}1 \\
(1.6 \%)\end{array}$ & 4 \\
\hline Necrotising Enterocolitis (NEC) & $\begin{array}{c}1 \\
(2.5 \%)\end{array}$ & $\begin{array}{c}1 \\
(1.6 \%)\end{array}$ & 2 \\
\hline
\end{tabular}

Table IV : Morbidities of Preterm Babies

\section{DISCUSSION}

In our study the hospital based incidence of preterm babies was $9.22 \%$ of total live birth with $19.34 \%$ extremely to very preterm ( $<32$ weeks) and $80.65 \%$ moderate to late preterm ( $\geq 32-37$ weeks).This is comparable to hospital incidence of preterm neonates in Tribhuwan University Teaching Hospital (TUTH) which was reported as $6.8 \%$ of total live births as shown by Shrestha et al ${ }^{6}$ with $10.5 \%$ severe preterm, $28.5 \%$ moderate preterm and $61 \%$ late preterm.

In our study, $43 \%$ of mothers were teenagers. In a study by Shrestha et al ${ }^{6}$ teenage pregnancy was reported in $34.7 \%$. Similarly, in another study by Onyaye et $\mathrm{al}^{7} 6.5 \%$ mothers were teenagers.

In our study $58 \%$ mothers were primi. In another study by Mohsenzadeh et al ${ }^{8} 56.3 \%$ of mother giving birth to preterm were primigravida which is comparable with our figures. The higher percentage of primi mother leading to preterm birthin the present study could be due to higher percentage of teenager and thereby leading to preterm birth due to early age of marriage, and poor perinatal care.

Majority of the mothers $(73 \%)$ in the present study had received inadequate antenatal care (ANC) visits $(<4)$. While study by Shrestha et al ${ }^{6}$ showed $52 \%$ of mother had inadequate antenatal visit.

Majority of the mothers in our study were found to have UTI (54\%). This is comparable to a study by Halimi et $\mathrm{al}^{9}$ where $43.5 \%$ of mothers had UTI.

A significant association (53\%) was seen between maternal anemia and preterm babies. Similar observation was made by Halimi et al ${ }^{10}$ who pointed that $48.3 \%$ of the mothers had anemia. A higher incidence of association of anemia in mothers giving preterm birth in our study may be because of the fact that majority of mothers belonged to teenage group and had inadequate $A N C$ visits.

In the present study, $41 \%$ of mothers had a history of antepartum hemorrhage. In a similar study by Shrestha et $\mathrm{al}^{6}$ $\mathrm{APH}$ wasseen in $23.3 \%$.The higher number of mothers with APH could be due to majority of mothers belonging to teenage group and inadequate antenatal checkup.

Out of 100 mothers, 33 (33\%) had a history of PIH. Our results are comparable to the results of Shrestha et al ${ }^{11}$ where $26 \%$ of mother had history of PIH. Similar result was also seen in a study by Onyaye et $\mathrm{al}^{7}$ where $23.9 \%$ mothers had PIH.

Majority of mothers in the present study had PPROM comprising $55 \%$. This is comparable to a study by Onyaye et al ${ }^{7}$ where $46.5 \%$ of mothers had PPROM. Similarly in a study by Halimi et al $^{9} 77.1 \%$ mothers of preterm had PPROM.

Regarding neonatal outcome, in the present study, $4 \%$ preterms were less than 1000 grams, $63 \%$ between $1000-1500$ grams and 33\% more than 1500 grams. In similar study done by Shrestha et al ${ }^{6} 6.7 \%$ of preterm babies were $<1000$ grams while $28.7 \%$ preterm babies were between $1000-1500$ grams and $64.7 \%$ preterm babies had weight more than 1500 gram. In another study by Das et $\mathrm{a}^{10} 19.4 \%$ of preterm had weight $<1.5 \mathrm{~kg}$ while $71.5 \%$ had weight between $1.5-2.5 \mathrm{~kg}$ and $9.1 \%$ had $>2.5 \mathrm{~kg}$ weight at the time of birth.

Out of 100 preterms in our study, 31 out of $40(77.5 \%)$ of extremely to very preterm babies survived whereas 57 out of $60(95 \%)$ of moderate to late preterm survived. And the total mortality was $12 \%$ with $22.5 \%$ of the extremely to late preterm and $5 \%$ of moderate to late preterm. In a similar study by Shrestha et a $\mathrm{a}^{11}$ overall mortality was found to be $12 \%$. In another study done by Onyaye et $\mathrm{al}^{7}$ the overall survival rate was $65.9 \%$. The survival rate was significantly higher in the 
mild preterm category, $83.8 \%$ compared to the very preterm, $47.8 \%$ and extremely preterm, $11.1 \%$.

The most important complication in our study was NNS in $68 \%$ of preterm, followed by Neonatal Jaundice 59\%, Birth Asphyxia $31 \%$, HMD 29\%, Apnea of Prematurity 10\%, Hypoglycemia 11\%, Anemia 8\%, Hypothermia 4\%, and Necrotizing Enterocolitis (NEC) $2 \%$.In similar study by Shrestha et al., ${ }^{6}$ sepsis was found in $66.7 \%$ followed by NNJ in58.8\%, Birth Asphyxia in 26.8\%, HMD in $23.5 \%$, NEC in $13.1 \%$, Hypothermia in $13.1 \%$, Hypoglycemia in $9.8 \%$, Hyponatremia in $6.5 \%$, Intra ventricular hemorrhage (IVH) in 3.9\%, Hypocalcemia in 3.9\% and Apnea in 3.3\%.

\section{LIMITATION}

This study only looked into the immediate outcome. Further study is needed to assess the long term (One year) outcome of these babies. The neurological outcomes are not assessed.

\section{CONCLUSION}

Significant maternal risk factors associated with preterm babies were inadequate antenatal visits, preterm premature rupture of membrane, teenage pregnancy, urinary tract infection, anemia, antepartum hemorrhage, pregnancy induced hypertension.

Common morbidities among preterm babies were Neonatal sepsis followed by Neonatal Jaundice, Birth Asphyxia, Hyaline Membrane Disease, Apnea of Prematurity, Hypoglycemia, Anemia, Hypothermia, and Necrotizing Enterocolitis. Overall mortality was $12 \%$. The main causes of mortality were NNS, HMD and Birth Asphyxia.

\section{REFERENCES}

1. Beck S, Wojdyla S, Say L, Betran AP, Merialdi M, Requejo JH, et al. The worldwide incidence of preterm birth: a systematic review of maternal mortality and morbidity. Bull. World Health Organ. 2010;88(1):31-8.

2. Blencowe $H$, Cousens $S$, Chou $D$, OestergaardM, Say L, Moller $A B$, et al. Borntoo soon: the global epidemiology of 15 million preterm births. Reprod Health. 2013;10(Suppl 1):S2.

3. Liu L, Johnson HL, Cousens S, Perin J, Scott S, Lawn JE, et al. Child Health Epidemiology Reference Group of WHO and UNICEF: Global, regional, and national causes of child mortality: an updated systematic analysis for 2010 with time trends since 2000. Lancet. 2012;379(9832):2151-61.

4. Macones GA. Prematurity: causes and prevention. In: Taeush HW, Ballard RA, Editors. Avery's diseases of the newborn. 8th ed. Philadelphia: Saunders; 2005 p.139-45.

5. Carlo WA. Prematurity and intrauterine growth restriction. In: Kleigman RM, Santon BF, Geme ST, Schor NF, Editors. Nelson textbook of pediatrics. 20th ed.Philadelphia: Elsevier; 2015. p.822.

6. Shrestha S, Dangol SS, Shrestha M, Shrestha RP. Outcome of preterm babies and associated risk factors in a hospital. J Nepal
Med Assoc. 2010;50(180):286-90.

7. Kunle-Olowu OE, Peterside O, Adeyemi OO. Prevalence and outcome of preterm admissions at the neonatal unit of a tertiary health centrein Southern Nigeria. Open J Paediatr.2014;4:67-75.

8. Mohsenzadeh A, Saket S, Karimi A. Prevalance of preterm neonates and risk factors. Iranian J Neonatology. 2011;2(2):3842.

9. Halimi Asl AA, Safari S, Hamrah MP. Epidemiology and Related Risk Factors of Preterm Labor as an Obstetrics Emergency. 2017; 5(1): e3.

10. Das A, Panda S, Ahanthem SS, Sourabh GD, Bhanu Pratap SG. Preterm birth: analysis of risk factors and neonatal outcome. Gynecology \& Obstetrics Case report. 2015; 1(1):1-5.

11. Shrestha L, Shrestha P. Mortality and Morbidity Pattern of preterm babies atTribhuvan University Teaching Hospital. J Nepal Paediatr Soc. 2013;33(3):201-5. 